\title{
Effects of domestic solid fuel combustion emissions on the biomarkers of homemakers in rural areas of the Fenwei Plain, China
}

\section{Rong Feng}

Xi'an Jiaotong University

Hongmei Xu ( $\boldsymbol{\nabla}$ xuhongmei@mail.xjtu.edu.cn)

Xi'an Jiaotong University https://orcid.org/0000-0002-4217-5066

\section{Kailai He}

Xi'an Jiaotong University

\section{Zexuan Wang}

Xi'an Jiaotong University

\section{Bei Han}

Xi'an Jiaotong University

\section{Ronghui Lei}

Xi'an Jiaotong University

Kin Fai Ho

The Chinese University of Hong Kong

Xinyi Niu

Xi'an Jiaotong University

Jian Sun

Xi'an Jiaotong University

\section{Bin Zhang}

Xi'an Jiaotong University

Pingping Liu

Xi'an Jiaotong University

\section{Zhenxing Shen}

Xi'an Jiaotong University

\section{Research}

Keywords: Solid fuel combustion, biomarker, health effect, rural household, Fenwei Plain

Posted Date: February 22nd, 2021

DOI: https://doi.org/10.21203/rs.3.rs-205167/v1 
License: (c) (i) This work is licensed under a Creative Commons Attribution 4.0 International License. Read Full License 


\section{Abstract \\ Background}

The health effects of heavy solid fuel use in winter in rural China are of concern. The effects of air pollution resulting from domestic solid fuel combustion in rural households on rural homemakers' biomarkers were revealed in this study.

\section{Methods}

In total, 75 female homemakers from rural areas of Guanzhong Basin, the Fenwei Plain, People's Republic of China, were randomly selected and divided into three groups (biomass users, coal users, and nonusers of solid fuel user [control group]). The differences in biological indicators, including 8-hydrox-2'deoxyguanosine (8-OHdG), interlukin-6 (IL-6), and tumor necrosis factor-alpha (TNF-a) in urine samples as well as blood pressure (BP, including systolic BP [SBP] and diastolic BP [DBP]) and heart rate (HR) among the groups in winter and summer were investigated using statistical analysis.

\section{Results}

IL-6, 8-OHdG, HR, SBP, and DBP were significantly higher in winter than in summer $(P<0.05)$ owing to the poor air quality resulted from the excessive use of solid fuels in winter. Significant seasonal differences in 8-OHdG, HR, and SBP were observed for both coal and biomass users. After the influence of confounders was removed, only IL-6 levels in the urine of solid fuel users were significantly higher than that of the control group.

\section{Conclusions}

IL-6 is a sensitive biomarker representing inflammatory responses to particulate matter emitted through household solid fuel combustion. Locally, excessive use of solid fuels in winter posed serious $\mathrm{PM}_{2.5}$ pollution in this area and adverse effects on inflammatory biomarkers in these rural homemakers and induced DNA damage related to oxidative stress.

\section{Introduction}

The burning of solid fuels for household heating and cooking in rural areas of China causes severe indoor air pollution (IAP). The key pollutants are $\mathrm{SO}_{2}, \mathrm{PM}_{2.5}$ (particulate matter [PM] with an aerodynamic diameter equal to or less than $2.5 \mu \mathrm{m}$ ), $\mathrm{PM}_{10}$ (particulate matter [PM] with an aerodynamic diameter equal to or less than $10 \mu \mathrm{m}$ ), volatile organic compounds (VOCs), and so on [1-4], which cause outdoor air pollution and the formation of haze, as well as health problems such as cardiovascular and 
respiratory diseases [5-10]. Zhou et al. revealed that domestic straw combustion is a major source of $\mathrm{SO}_{2}(57.8 \%), \mathrm{PM}_{10}$ (42.8\%), $\mathrm{PM}_{2.5}$ (42.0\%), $\mathrm{CO}$ (58.1\%), and $\mathrm{CO}_{2}$ (38.8\%) emissions in mainland China [11]. A study demonstrated that household cooking using coal, wood, or other solid fuels may contribute up to $12 \%$ of ambient $\mathrm{PM}_{2.5}$ in sub-Saharan Africa [12]. Domestic solid fuel combustion is also a major contributor to air pollution in rural northwest China [13]. Huang et al. revealed that wood burning in winter contributed to approximately $41 \%$ of personal $\mathrm{PM}_{2.5}$ exposure in Yunnan Province of China [14]. By studying data from various summarized emission inventories, Li et al. found that among all anthropogenic emission sources, the contributions of $\mathrm{CO}, \mathrm{PM}_{2.5}$, and polycyclic aromatic hydrocarbons (PAHs) generated by household coal and biomass emissions were approximately $30 \%, 30 \%$, and $60 \%$, respectively, [15].

IAP from solid fuel combustion ranked fifth among the top 15 health risk factors in China in 2012, and its contribution to health hazards approached $7 \%$, which was only $1 \%$ lower than outdoor air pollution [16]. Exposure to PM, CO, and NOx released from the incomplete combustion of solid fuel can increase the risk of respiratory infections and cardiovascular events [17]. Yin et al. revealed that in 2017, 271,089 deaths in China were attributed to household air pollution from solid fuels [18]. Sun et al. revealed that the noncancer risk from VOC exposure among rural residents in traditional kitchens in winter in Guanzhong Basin was as high as 7,600 [3]. Epstein et al. observed that compared with the use of clean fuels, the use of high-pollution fuels (coal, biomass, or kerosene) in households had a significantly higher association with the risk of neonatal death [19]. Systematic seasonal comparisons of the biomarkers of Chinese residents who use different domestic solid fuels are lacking.

Studies have revealed that inflammation is a key mechanism of human diseases caused by PM exposure. As the main inflammatory cytokines, interleukin (IL) and tumor necrosis factor-alpha (TNF-a) have been widely investigated in epidemiological and biological studies [20-24]. A study focusing on rural India showed that interleukin-6 (IL-6) and TNF-a levels in the serum of individuals from households that used biomass fuels were higher than in those from households that used liquefied petroleum gas (LPG) [25]. Jiang et al. demonstrated a close association between long-term exposure to traffic-related air pollutants and systemic inflammatory markers, such as IL-6 and IL-10 in serum [26]. Furthermore, exposure to air pollutants can disturb toxic pathways and damage human health, such as by inducing oxidative stress [24]. 8-Hydrox-2'-deoxyguanosine (8-OHdG) is a biomarker of oxidative stress and oxidative DNA damage associated with chemical exposure [27], and it is often used to evaluate the oxidative damage caused by personal exposure to air pollutants [27-30]. Through a comparison of coke plant workers and farmers $25 \mathrm{~km}$ away from the coke plants, Fan et al. found that severe exposure to PAHs, benzene, and toluene (BT) was related to a sharp increase of urinary 8-OHdG level [31].

Guanzhong (Shaanxi Province) is located on the Fenwei Plain, which was designated a key air pollution control area by the Ministry of Ecology and Environment of the People's Republic of China in 2018. Related measures were introduced, including the promotion of electric vehicles for green transportation, the implementation of guidelines for ultralow industrial emissions, and the control of VOC and PM emissions, to improve ambient air quality in urban areas of the Fenwei Plain, which makes IAP issue in 
rural area particularly prominent. Among rural households, solid fuels such as coal, maize straw, wheat straw, and wood are commonly used for cooking and home heating in winter [3]. In Shaanxi, the total amount of biomass available annually was approximately equivalent to 11 million t of standard coal, and the total amount of coal consumed in 2019 was approximately 98 million $\mathrm{t}[32,33]$. Solid fuel combustion in rural households without filtering systems is associated with low emission height (similar to the height of humans, which increases the inhalation of such pollutants) and high emission factors; in such circumstances, the inhalation of a small amount of such pollutants can cause severe health problems. Moreover, personal activities, including the ignition of solid fuels for heating or cooking, could cause $40 \%$ higher exposure to $\mathrm{PM}_{2.5}$ compared with that in standard indoor and outdoor conditions in rural Guanzhong [34]. In-depth research is urgently required to evaluate the health effects of emissions from solid fuel combustion.

We conducted epidemiological surveys involving 75 female homemakers in rural Guanzhong, Fenwei Plain to investigate the health effects of solid fuel combustion emissions. To determine seasonal variations and differences among households that burned coal, biomass, and nonsolid fuels, we compared biomarker levels in participants using urine samples as well as blood pressure (BP) and heart rate (HR) measurements. The results of our study provide a theoretical basis for energy structure reforms in rural areas of the Fenwei Plain and enable a deeper understanding of the negative health effects of air pollution.

\section{Methods}

\section{Study design and basic information}

Physical examinations, urine sample collection, and a questionnaire survey of selected female homemakers responsible for heating and cooking at home were performed synchronously in three adjacent villages in Lantian County, Shaanxi, during the winter (January 4 to 8) and summer (July 5 to 9 ) of 2019 . In total, $87 \%$ of rural residents in the study area used traditional stoves or bed stoves (called kang in Mandarin Chinese) heated with solid fuels (i.e., biomass [branches, wheat straw, maize straw, or wood, Fig S1b] or coal [Fig S1c]) in winter. Traditional cooking stoves heated by coal or biomass fuels were used by $65 \%$ of the studied households in these villages during the entire year. The remaining residents in the study area used electrical energy for heating and cooking (Fig S1d).

\section{Participants and sampling}

In winter, 75 female homemakers aged from 40 to 77 years in the three target villages were randomly selected to participate in the survey. In total, 72 housewives participated in the repeated survey in summer. During the sampling periods, a trained research assistant conducted the questionnaire survey, physical examinations, and urine sample collection (Fig. S1a). All participants signed informed consent forms before participating. The study was approved by the Biomedical Ethics Committee of the Health Science Center of Xi'an Jiaotong University, China (registration number: 2018 - 532). 
The questionnaire survey had a face-to-face question and answer format. The questions inquired about basic information (age, height, weight, education level, and smoking and drinking status), physical condition (respiratory symptoms in the last 3 days, chronic disease history, and recent medication use) and living environment and habits (house size and type, ventilation habits, frequency of outdoor activities, presence of indoor pets and plants, use of incense and mosquito coils, heating fuel and stove, and cooking fuel and stove).

After the survey was conducted, an electronic sphygmomanometer (Omron J732, Japan) was used to measure the morning BP (systolic BP [SBP] and diastolic BP [DBP]) and HR of each participant. The participants were asked to avoid strenuous exercise half an hour before measurements. Each participant sat down and exposed their arm so that measurements could be taken. In the following sections, we used "health indicators" to refer to BP, including SBP, DBP, and HR.

After BP measurements, each participant was given a sealed and sterilized urine tube to collect morning urine the next day; they were asked to return it to the research assistant immediately after collection. Urine samples were transferred to the laboratory in $a 4^{\circ} \mathrm{C}$ incubator within 4 hours and then stored at $-80^{\circ} \mathrm{C}$ for subsequent biomarker analysis. A total of 144 urine samples were collected from 72 participants (one each in winter and summer).

\section{Biomarker analyses}

Three biomarkers in the urine samples were analyzed, namely 8-OHdG, IL-6, and TNF-a. Each urine sample was thawed at room temperature and centrifuged at $1000 \mathrm{rpm}$ for $10 \mathrm{~min}$. Subsequently, the supernatant was extracted for further analysis. An ELISA kit from ABclonal Biotechnology Co., Ltd (Wuhan, China) was used to analyze the aforementioned biomarkers. All tests were performed according to manufacturer instructions. A replicate analysis was conducted for each sample and each biomarker. The creatinine levels in urine samples were measured using a creatinine $(\mathrm{Cr})$ assay kit (sarcosine oxidase; Nanjing Jiancheng Bioengineering Institute, Nanjing, China) to standardize the concentrations of biomarkers so we could control urine flow rate variations. Biomarker concentrations were expressed as $\mu \mathrm{g} / \mathrm{mol} \mathrm{UCr}$.

\section{Ambient air pollution data and meteorological parameters}

The daily average concentrations of $\mathrm{PM}_{2.5}, \mathrm{PM}_{10}, \mathrm{CO}, \mathrm{NO}_{2}, \mathrm{O}_{3}$, and $\mathrm{SO}_{2}$; the air quality index (AQI); and meteorological data, namely average air temperature (AT), relative humidity (RH), and wind speed (WS) during the sampling periods were obtained from a database containing readings from a nearby national air quality monitoring station (https://www.aqistudy.cn/historydata/monthdata).

\section{Statistical analysis}

Excel 2019 (Microsoft Corporation, Redmond, Washington, USA) was used for data input and sorting, SPSS19.0 (International Business Machines Corporation, Armonk, New York, USA) was used for 
statistical analysis, and Origin 2019 (OriginLab, Northampton, Massachusetts, USA) was used for plotting. Median and interquartile range (IQR) values were used to describe the characteristics of data calculated by Origin 2019. A paired $t$ test and chi-squared test were performed to analyze the basic participant information. Statistically and significantly differences were respectively denoted by $P<0.05$ $(*)$ and $P<0.001(* *)$.

Biomarker data were first subjected to a normal distribution, and paired $t$ tests for winter and summer were performed for those with normal distributions. The distributions of biomarkers were analyzed using a rank sum test to determine whether significant differences existed between two season groups. Additionally, to determine the correlation between biomarkers and confounders, Pearson's correlation coefficient was applied for continuous variables, and Spearman's correlation coefficient was used for noncontinuous numerical variables. Subsequently, the influence of factors that could interfere with the measurement of various biomarkers was removed, and a generalized linear model was used to determine the effect of fuels on biomarkers. Some respondents in our survey used antihypertensive drugs for hypertension, and this would have affected their BP and HR; as a result, comparisons of these biomarkers between different fuel use groups were not conducted.

\section{Results}

\section{The study population}

A total of 75 women were included in the study, of which 3 dropped-out. The statistical analysis results related to the basic information of 72 valid participants are summarized in Table 1 . There had an average age of $61 \pm 9$ years and BMI of $24.9 \pm 3.55 \mathrm{~kg} / \mathrm{m}^{2}$, respectively. In terms of educational attainment, $72.2 \%$ of participants had only a primary school education or below, $25 \%$ of participants had a secondary school education, and $2.8 \%$ had an undergraduate education. All participants were nonsmokers, only $37.5 \%$ and $26.4 \%$ were exposed to second-hand smoke from family members in winter and summer, respectively. Table 1 reveals that in the 3 days before sampling, $44.4 \%$ participants in summer and $31.9 \%$ participants in winter had respiratory symptoms such as cold, cough, or fever. There had no statistical difference in number of participants with chronic diseases (hypertension, cardiovascular diseases, respiratory and other diseases) in summer and winter groups. Furthermore, data on alcohol consumption, illness and medication, frequency of outdoor activities, window opening for ventilation, and the presence indoor pets and plants were comparable in winter and summer $(P>0.1)$. 
Table 1

Characteristics of the participants in winter and summer.

\begin{tabular}{|c|c|c|c|}
\hline & $\begin{array}{l}\text { Winter }(\mathrm{N}= \\
72)\end{array}$ & $\begin{array}{l}\text { Summer }(\mathrm{N}= \\
72)\end{array}$ & $P$-value ${ }^{1}$ \\
\hline Age (years old) & $61 \pm 9$ & & \\
\hline BMI & $24.9 \pm 3.55$ & & \\
\hline \multicolumn{4}{|l|}{ Education } \\
\hline Primary and below & $52(72.22 \%)$ & & \\
\hline Middle school & $18(25 \%)$ & & \\
\hline College or higher & $2(2.78 \%)$ & & \\
\hline Smoking status-Never smoke & 72 & 72 & \\
\hline $\begin{array}{l}\text { Number of cigarettes smoked by family members per } \\
\text { day }\end{array}$ & $27(37.5 \%)$ & $19(26.4 \%)$ & 0.102 \\
\hline$<5$ & 6 & 5 & \\
\hline $5 \sim 10$ & 13 & 8 & \\
\hline$>10$ & 7 & 6 & \\
\hline Alcohol drinking & 1 & 1 & \\
\hline Respiratory symptoms in the past three days & 32 & 23 & 0.123 \\
\hline Disease status & & & 0.749 \\
\hline Hypertension & 28 & 30 & \\
\hline Cardiopathy & 7 & 9 & \\
\hline Respiratory disease & 4 & 4 & \\
\hline Other disease & 9 & 2 & \\
\hline Medication & 30 & 42 & \\
\hline Housing area $\left(\mathrm{m}^{2}\right)$ & $119.48 \pm 51.19$ & & \\
\hline House with a yard & 24 & & \\
\hline Outdoor physical activity & & & 0.785 \\
\hline None or sometimes & 46 & 52 & \\
\hline Often & 8 & 16 & \\
\hline
\end{tabular}

${ }^{1}: P$-value was got from paired sample $t$ test for continuous variables and chi-squared test for nonnumeric variables. 


\begin{tabular}{|c|c|c|c|}
\hline & $\begin{array}{l}\text { Winter }(\mathrm{N}= \\
72)\end{array}$ & $\begin{array}{l}\text { Summer }(\mathrm{N}= \\
72)\end{array}$ & $P$-value ${ }^{1}$ \\
\hline Everyday & 9 & 0 & \\
\hline Opening window for ventilation & & & 0.981 \\
\hline None or sometimes & 49 & 3 & \\
\hline Often & 9 & 22 & \\
\hline Everyday & 9 & 44 & \\
\hline Keeping pets & 18 & 19 & 0.849 \\
\hline Keeping plants & 14 & 16 & 0.682 \\
\hline Use of incense or mosquito coil & & & $\dot{0.001 * *}$ \\
\hline None or sometimes & / & 12 & \\
\hline Often & / & 4 & \\
\hline Everyday & l & 31 & \\
\hline \multicolumn{4}{|l|}{ Main household energy } \\
\hline Biomass & 24 & 24 & l \\
\hline Coal & 27 & 27 & l \\
\hline Non-solid fuel & 11 & 11 & l \\
\hline Fuel consumption $(\mathrm{kg} / \mathrm{d})$ & & & $<.001^{* *}$ \\
\hline Biomass & 24.5 & 5.1 & \\
\hline Coal & 4.8 & 0.9 & \\
\hline \multicolumn{4}{|l|}{ Main heating method } \\
\hline Traditional indoor coal stove & 19 & / & l \\
\hline Biomass stove connected to heated brick bed & 20 & / & / \\
\hline $\begin{array}{l}\text { New type heating stove (secondary air distribution } \\
\text { furnace) }\end{array}$ & 20 & / & l \\
\hline Electric heating equipment & 8 & / & / \\
\hline None & 3 & / & / \\
\hline
\end{tabular}


Table 1 shows that significant differences existed in the subjects who used of mosquito coils and solid fuel between winter and summer $(P<0.001)$. Of the 72 participants, 11 who used various solid fuels at home were excluded from the comparison of different fuel groups (Sect. 3.4). The participants were divided into groups of solid fuel users, i.e., 24 biomass users (Fig. S1b) and 27 coal users (Fig. S1c), and nonsolid fuel users (Fig. S1d; control group; 10 participants). Data were excluded on households that used nonsolid fuels; in the remaining households, the daily average consumption of solid fuels (biomass and coal) in winter was approximately five times that in summer $(P<0.001)$.

\section{Variations in air quality and meteorological parameters}

The ambient concentrations of air pollutants during the sampling period are shown in Fig. 1. Significant differences between winter and summer $(P<0.001)$ were observed for the six studied air pollutants (Fig. 1a). The median concentrations of $\mathrm{PM}_{2.5}, \mathrm{PM}_{10}, \mathrm{SO}_{2}, \mathrm{CO}$, and $\mathrm{NO}_{2}$ during the winter sampling period were all markedly higher than those in summer. The median concentration of $\mathrm{PM}_{2.5}$ in winter was more than nine times higher than that in summer (winter: $183 \mu \mathrm{g} / \mathrm{m}^{3}, \mathrm{IQR}=110-216 \mu \mathrm{g} / \mathrm{m}^{3}$; summer: 19 $\mu \mathrm{g} / \mathrm{m}^{3}, \mathrm{IQR}=13-25 \mu \mathrm{g} / \mathrm{m}^{3}$ ). The daily average $\mathrm{PM}_{2.5}$ concentration in winter in this study area was 2.5 times higher than China's 24-h Ambient Air Quality Standard (AAQS; $75 \mu \mathrm{g} / \mathrm{m}^{3}$, GB 3095-2012) [35]. However, $\mathrm{O}_{3}$ differed from other air pollutants in that the median concentration was approximately five times higher in summer than in winter (winter: $33 \mu \mathrm{g} / \mathrm{m}^{3}$, IQR = 19-45 $\mu \mathrm{g} / \mathrm{m}^{3}$; summer: $161 \mu \mathrm{g} / \mathrm{m3}$, IQR = $\left.139-185 \mu \mathrm{g} / \mathrm{m}^{3}\right)$. The median concentration of $\mathrm{O}_{3}$ in summer was almost the same as the specified standard $\left(160 \mu \mathrm{g} / \mathrm{m}^{3}\right)$ [35]. Figure $1 \mathrm{~b}$ shows that in the study area, PM was the dominant pollutant in winter, whereas $\mathrm{O}_{3}$ was the dominated pollutant in summer.

Figure 2a shows that the AQI in winter was significantly higher than in summer $(P<0.001)$. According to the AQI, air quality can be categorized as good ( $0-50$, green), moderate $(51-100$, yellow), unhealthy for sensitive groups (101-150, orange), unhealthy (151-200, red), very unhealthy (201-300, purple), and hazardous (301-500, dark red) [36]. The percentage distributions of AQI categories during the sampling period in winter and summer are shown in Fig. $2 \mathrm{~b}$. In winter, $42.1 \%$ and $15.8 \%$ of the sampling days were categorized as very unhealthy and hazardous, respectively. Moreover, $52.6 \%$ of the summer sampling days were categorized as unhealthy for sensitive groups.

Figure 3 compares the meteorological parameters (AT, $\mathrm{RH}$, and WS) between winter and summer during the sampling period. No significant differences were noted in RH or WS, but as expected, AT was significantly higher in summer $\left(\right.$ median $=26^{\circ} \mathrm{C}, \mathrm{IQR}=20$ to $\left.29.5^{\circ} \mathrm{C}\right)$ than in winter $\left(\right.$ median $=-1.5^{\circ} \mathrm{C}, \mathrm{IQR}=$ -4 to $\left.2^{\circ} \mathrm{C}\right)$.

\section{Seasonal variations in biomarkers and health indicators}


As shown in Fig. 4, the median concentration of IL-6 in winter was $0.42 \mu \mathrm{g} / \mathrm{mol} \mathrm{UCr}$ (IQR $=0.18-0.91$ $\mu \mathrm{g} / \mathrm{mol} \mathrm{UCr}$ ); this was over twice that in summer (median $=0.20 \mu \mathrm{g} / \mathrm{mol} \mathrm{UCr}$, IQR $=0.10-0.34 \mu \mathrm{g} / \mathrm{mol}$ $\mathrm{UCr}$ ). The median 8-OHdG concentrations in winter and summer were $24.81 \mu \mathrm{g} / \mathrm{mol} \mathrm{UCr}(\mathrm{IQR}=12.75-$ $38.27 \mu \mathrm{g} / \mathrm{mol} \mathrm{UCr}$ ) and $13.46 \mu \mathrm{g} / \mathrm{mol} \mathrm{UCr}(\mathrm{IQR}=7.62-22.02 \mu \mathrm{g} / \mathrm{mol} \mathrm{UCr}$ ), respectively. For both biomarkers, the winter values were significantly higher than those in summer $(P<0.001)$. The median concentration of TNF-a in summer (median $=0.56 \mu \mathrm{g} / \mathrm{mol} \mathrm{UCr}$, IQR $=0.37-0.80 \mu \mathrm{g} / \mathrm{mol} \mathrm{UCr}$ ) was 1.4 times that in winter (median $=0.40 \mu \mathrm{g} / \mathrm{mol} \mathrm{UCr}, \mathrm{IQR}=0.28-0.64 \mu \mathrm{g} / \mathrm{mol} \mathrm{UCr}$ ), indicating a statistically difference $(P<0.05)$ between these seasons. Figure 4 also presents a comparison of the HR and BP of the participants in winter and summer. The median SBP value in winter $(143 \mathrm{~mm} \mathrm{Hg}, I Q R=128-160 \mathrm{~mm}$ $\mathrm{Hg}$ ) was 1.6 times that in summer $(88 \mathrm{~mm} \mathrm{Hg}, \mathrm{IQR}=73-115 \mathrm{~mm} \mathrm{Hg})$, whereas the median values for DBP $(83 \mathrm{~mm} \mathrm{Hg})$ and HR (84 beats per minute [BPM]) were both 1.1 times than those in summer (DBP: $74.5 \mathrm{~mm}$ Hg; HR: 79 BPM). The median HR, SBP, and DBP values in winter were all significantly higher than those in summer $(P<0.001)$.

\section{Impact of burning different fuels on biomarkers}

A comparison of average biomarker values between winter and summer among different fuel use groups is presented in Fig. 5 and Table S1. The combustion of different fuels had diverse effects on biological markers. IL-6 and 8-OHdG levels in winter were higher than those in summer for all three fuel groups. For coal users, significant differences were observed in IL-6 $(P<0.001)$ and 8-OHdG $(P<0.05)$ levels between winter and summer. For biomass users, between winter and summer, statistical differences in 8-OHdG $(P$ $<0.05)$ levels and nonsignificant differences in IL-6 levels $(P>0.05)$ were noted. The TNF-a levels of biomass users were statistically higher in summer than in winter $(P<0.05)$; for coal users and the control group, we did not observe significant seasonal variations in TNF-a levels.

After the removal of confounders (i.e., age, BMI, and educational attainment), the influence of solid fuel combustion on biomarkers differed between winter and summer (Table 2). Even after confounders were removed, IL-6 levels were higher in the solid fuel group than in the control group in both winter and summer. Patterns of 8-OHdG and TNF-a were similar in winter, with coal users having higher values than the other two groups. However, in summer, the average 8-OHdG level of the control group was the highest, followed by the biomass users and coal users. Biomass users had the highest TNF-a level, followed by non-solid fuel users (control group) and coal users. 
Table 2

The biomarkers ( $\mu \mathrm{g} / \mathrm{mol} \mathrm{UCr}$ ) with $95 \%$ confidence interval $(\mathrm{Cl})$ after removing confounding factors.

\begin{tabular}{|c|c|c|c|c|c|c|}
\hline & \multicolumn{3}{|c|}{ Winter $(N=61)$} & \multicolumn{3}{|c|}{ Summer $(\mathrm{N}=61)$} \\
\hline & Biomass & Coal & $\begin{array}{l}\text { Non-solid } \\
\text { fuel }\end{array}$ & Biomass & Coal & $\begin{array}{l}\text { Non-solid } \\
\text { fuel }\end{array}$ \\
\hline & $N=24$ & $N=27$ & $N=10$ & $N=24$ & $N=27$ & $N=10$ \\
\hline $\begin{array}{l}\text { IL-6 }(\mu \mathrm{g} / \mathrm{mol} \\
\text { UCr) }\end{array}$ & 0.68 & 0.73 & 0.40 & 0.49 & 0.27 & 0.26 \\
\hline $95 \% \mathrm{Cl}$ & $\begin{array}{l}0.44- \\
0.92\end{array}$ & $\begin{array}{l}0.48- \\
0.97\end{array}$ & $0.01-0.80$ & $\begin{array}{l}0.26- \\
0.71\end{array}$ & $\begin{array}{l}0.04- \\
0.48\end{array}$ & $0.07-0.62$ \\
\hline $\begin{array}{l}\text { 8-OHdG }(\mu \mathrm{g} / \mathrm{mol} \\
\text { UCr) }\end{array}$ & 18.93 & 30.18 & 26.43 & 22.71 & 14.28 & 25.72 \\
\hline $95 \% \mathrm{Cl}$ & $\begin{array}{l}11.40- \\
26.46\end{array}$ & $\begin{array}{l}22.42- \\
37.93\end{array}$ & $\begin{array}{l}13.72- \\
39.13\end{array}$ & $\begin{array}{l}13.21- \\
32.21\end{array}$ & $\begin{array}{l}5.17- \\
23.38\end{array}$ & $\begin{array}{l}11.05- \\
40.38\end{array}$ \\
\hline $\begin{array}{l}\text { TNF-a }(\mu \mathrm{g} / \mathrm{mol} \\
\text { UCr) }\end{array}$ & 0.37 & 0.67 & 0.57 & 0.90 & 0.61 & 0.76 \\
\hline $95 \% \mathrm{Cl}$ & $\begin{array}{l}0.20- \\
0.54\end{array}$ & $\begin{array}{l}0.49- \\
0.88\end{array}$ & $0.28-0.86$ & $\begin{array}{l}0.52- \\
1.28\end{array}$ & $\begin{array}{l}0.24- \\
0.97\end{array}$ & $0.17-1.35$ \\
\hline
\end{tabular}

\section{Discussion}

We obtained the background concentrations of six air pollutants in ambient air and meteorological data during the sampling period from a nearby environmental monitoring station. PM, including $\mathrm{PM}_{2.5}$ and $\mathrm{PM}_{10}$, was the main air pollutant in winter, markedly exceeding the limits of China's AAQS (Fig. 1). The $\mathrm{AQI}$ in winter was considerably higher than that in summer, and as expected, PM was the dominant pollutant in the sampling period of winter (Fig. 2). High AQI may be attributable to the poor dispersal conditions of low temperature $\left(1.5^{\circ} \mathrm{C}\right)$ and WS $(6.0 \mathrm{~km} / \mathrm{h})$ as well as the increase in energy demand during winter (Fig. 3). Moreover, although most urban residences in Xi'an use central heating systems fueled by natural gas, solid fuels are still the mainstay for rural household heating in this area. In the studied villages, the amount of biomass fuel used for heating in winter was approximately $400 \mathrm{t}$, and domestic coal consumption was approximately $90 \mathrm{t}$. Because the sampling site is somewhat remote, it was not markedly affected by vehicle or industrial emissions. Therefore, apart from meteorological factors, the markedly elevated $\mathrm{AQI}$ and accompanying emissions of $\mathrm{PM}, \mathrm{SO}_{2}, \mathrm{CO}$, and $\mathrm{NO}_{2}$ in winter were mainly attributed to solid fuel burning in rural households.

During this decade, the northern regions of China, including the Fenwei Plain, are often affected by severe haze episodes in winter $[5,37]$. Tian et al. estimated that emission levels from primary residential coal combustion were $757 \mathrm{Gg}$ of $\mathrm{PM}_{2.5}, 237 \mathrm{Gg}$ of organic carbon (OC), and $343 \mathrm{Gg}$ of elemental carbon in China in 2012 [38]. Wu et al. demonstrated that coal and biomass burning in winter were the main 
sources of OC in $\mathrm{PM}_{2.5}$ in rural Beijing, accounting for $24-34 \%$ and $20 \%$ of OC, respectively [39]. Liao et al. also proved that $39 \%$ (95\% confidence interval [Cl]: $26-54 \%$ ) of hourly average $\mathrm{PM}_{2.5}$ in the ambient environment was caused by heating-related emissions in the previous hour during winter in Beijing [2]. Moreover, apart from general indoor and outdoor $\mathrm{PM}_{2.5}$ concentrations, high personal $\mathrm{PM}_{2.5}$ exposure levels were mainly related to solid fuel burning for household heating and cooking [34]. Therefore, necessary measures are urgently required to control domestic solid fuel emissions in northern China, especially in winter.

Because rural female homemakers generally spend a considerable amount of time indoors, and often near stoves, they are the population most affected by indoor air pollutants from solid fuel combustion in this area of rural China in winter [34]. In this study, the participants' SBP, DBP, and HR in winter were significantly higher than they were in summer $(P<0.001)$ (Fig. 4), possibly as a result of the short-term impact of air pollutants emitted from solid fuel combustion in winter. These higher levels might be explained by the theory that cardiac output and peripheral vascular resistance are affected by fluctuations in air pollutant concentrations [40]. Although the mechanisms linking BP to short- or longterm exposure to air pollutants may be different, current results revealed a significant association between the use of solid fuels and increased BP through sympathetic nervous system activation. Pangaribuan et al. demonstrated that air pollutants were significantly and positively associated with HR and SBP but not with DBP [41]. By contrast, Zhao et al. found that $\mathrm{PM}_{2.5}$ was not significantly associated with DBP [42].

In the urine samples collected from participants in summer and winter, we identified significantly higher levels of two biomarkers (IL-6 and 8-OHdG) indicating inflammation and oxidative stress in the winter samples (Fig. 5 and Table S1). The excessive use of solid fuels in winter had negative effects on the health biomarkers of these rural homemakers than in summer. This is consistent with the results of several studies. A seasonal toxicology study conducted in Delhi, India, revealed that cells exposed to PM in winter had higher levels of IL-6 compared with such levels in all other seasons, indicating that PM toxicity in winter was exacerbated by the burning of firecrackers and open agricultural fires [43]. In addition, a study in Milan reported that winter $\mathrm{PM}_{2.5}$, which was mostly contributed by fuel combustion, caused an increase in the IL-6 synthesis of human bronchial epithelial BEAS-2B cells after $24 \mathrm{~h}$ exposure [44]. According to Yao et al., the level of 8-OHdG in the urine of rural women in the heating season (from November to late March) was higher than in the nonheating season (from May to August) in Gansu, China [45]. This differs from our finding of lower TNF-a levels in winter than in summer. The specific mechanism remains unclear; more research is required to elucidate this.

After we used generalized linear models to remove interference from confounding factors (Table 2), our data showed that the IL- 6 levels of the solid fuel group in winter and summer were both higher than those of the control group during these seasons. One study has reported that women who used biomass for cooking showed higher IL-6 levels than a control group [25]. A similar result was observed in another study in South Africa; those who burned wood in the home had higher plasma IL-6 levels than electricity 
users did [23]. These results may help explain the association between solid fuel combustion and inflammation [22]. After exposure to PM, airway inflammation was presumably induced after inflammatory cells were circulated and trafficked to the airway, causing increased IL-6 [21]. Certain substances in $\mathrm{PM}_{2.5}$ emitted from solid fuel combustion may have caused increased IL-6 levels in our study [22].

No obvious trends related to TNF-a or 8-OHdG levels between solid fuel users and the control group were observed in this study (Table 2). Researchers have not identified consistent patterns related to these two biomarkers. For example, Wang et al. did not observe a significant association between PM and TNF-a [46]. A Peruvian study showed no significant difference in oxidative stress biomarkers between control (traditional open fire stoves) and intervention groups (improved stove, which was expected to reduce exposure to biomass smoke) [29]. However, an Indian study reported that women cooking with biomass had $72 \%$ higher plasma TNF-a levels than women cooking with LPG did [47]. Compared with the cleaner fuel combustion (such as electricity, LPG), solid fuel combustion can release higher levels of air pollutants (such as $\mathrm{PM}_{2.5}$ and $\mathrm{NO}_{\mathrm{x}}$ ), and this may increase the risk of neurological diseases through oxidative stress and neuroinflammation $[48,49]$. Another study showed that long-term exposure to severe air pollution can cause accumulated DNA damage, and a dose-response relationship with continuous exposure was observed [50]. Explaining the inconsistent findings described herein is difficult because they involve many complex factors, including population characteristics, sample size, and geographical and temporal differences [50]; more in-depth research based on a large sample size is required.

Although the mechanism through which PM induces health damage has not been adequately confirmed, the results of related studies confirm the involvement of several biological pathways; for example, PM exposure can induce acute cardiovascular events [40] and exacerbate of chronic diseases [51]. Many toxicological experiments have been conducted to investigate the mechanism of health damage caused by different size PMs $[52,53]$. A study indicated that air pollution, especially $\mathrm{PM}_{2.5}$, can promote oxidative stress and inflammation to induce DNA damage [54]. Shrine et al. found that particles of different sizes can damage the DNA of human peripheral blood lymphocytes, and the smaller the particles are, the greater is the damage to DNA [55]. A study proved that inhalation of smoke from solid fuel combustion alters sputum cytology and increases airway inflammation and oxidative stress, all of which might amplify the tissue-damaging reaction to long-term exposure [53]. On the basis of the aforementioned findings, the negative effects of air pollution from solid fuel combustion on BP, HR, TNF-a, and 8-OHdG were not as obvious or as strong as the effects on IL-6.

$\mathrm{O}_{3}$ is a powerful oxidant that has various harmful effects on human health $[56,57]$. It was the dominant air pollutant in summer in the present study (Fig. 1), although its concentration was comparable to China's 8-h AAQS. In this study, only TNF-a levels in summer were higher than those in winter $(P<0.05$, Fig. 4), especially among biomass users $\left(P<0.05\right.$, Fig. 5). We did not observe an impact of elevated $\mathrm{O}_{3}$ concentrations in summer on other biomarkers and health indicator. Epidemiological research and animal experiments have demonstrated that short-term acute exposure to high concentrations of $\mathrm{O}_{3}$ causes 
respiratory symptoms, including lung function alterations, airway hyperresponsiveness, and respiratory inflammation $[58,59]$. Wang et al. found that $\mathrm{O}_{3}$ increased the inflammation and oxidative stress induced by $\mathrm{PM}_{2.5}$ in the lungs of rats [56]. An epidemiological study of 10-year-old children reported that shortterm $\mathrm{O}_{3}$ exposure was not associated with systemic IL-6 levels, but $\mathrm{O}_{3}$ exposure had some effect on airway inflammation in those children [57]. Inhalation of $\mathrm{O}_{3}$ can cause an increase in airway neutrophilia [60]; airway surface liquid macrophage linkage to receptors on epithelial cells is stimulated by the products of secondary lipid ozonation, which are thought to secrete proinflammatory cytokines, including TNF-a [61].

The main limitations of the present study relate to human labor resources and material constraints. Air pollutant levels from nearby environmental monitoring sites instead of personal exposure were used as the exposure levels; this may have led to the misclassification of nondifferential exposure. In some environmental epidemic research, ambient air pollution data have also been used to represent personal exposure levels [9]. Although we controlled for demographic characteristics, some uncontrollable variables such as genetic variables and personal immunity could not be controlled, and this may have led to inaccurate results. At least, this study is the first to investigate the health effects of $\mathrm{PM}$ and $\mathrm{O}_{3}$ related to the combustion of household solid fuels, based on biomarkers of inflammation, in individuals living in underdeveloped areas of China.

\section{Conclusions}

On the basis of PM levels from solid fuel combustion during winter (from November to March) in three villages of Fenwei Plain, China, we compared the health effects of the combustion of different solid fuels in summer and winter and their associations with biomarkers. We found that the excessive use of solid fuels in winter and associated levels of $\mathrm{PM}_{2.5}$ had an adverse effect on inflammatory cytokines. The IL- 6 levels of solid fuel users were markedly higher than those of the control group, indicating that IL- 6 is an ideal and sensitive biomarker of PM-related health effects impacted by the household solid fuel combustion. Moreover, owing to several factors, such as reduced solid fuel usage, altered cooking habits, and seasonal differences, we did not observe an influence of fuel types in summer on the aforementioned biomarkers. Our research contributes to explanations of inflammatory responses to solid fuel burning and the related risk of cardiovascular diseases. These findings are crucial for improving household energy usage habits, especially in the winter heating season. Some control measures should be adopted to ensure that rural households use cleaner fuels or use densified biomass briquette fuels appropriately for heating and cooking in Northern China.

\section{Abbreviations}

IAP: Indoor air pollution; PM: Particulate matter; $\mathrm{PM}_{2.5}$ : Particulate matter with aerodynamic diameter equal to or less than $2.5 \mu \mathrm{m} ; \mathrm{PM}_{10}$ : Particulate matter with aerodynamic diameter equal to or less than 10 $\mu \mathrm{m}$; VOCs: Volatile organic compounds; PAHs: Polycyclic aromatic hydrocarbons; IL: Interleukin; TNF-a: 
Tumor necrosis factor-alpha; IL-6: Interleukin-6; LPG: Liquefied petroleum gas; IL-10: Interleukin-10; 8OHdG: 8-Hydrox-2'-deoxyguanosine; BT: Benzene and toluene; BP: Blood pressure; HR: Heart rate; SBP: Systolic blood pressure; DBP: Diastolic blood pressure; Cr: Creatinine; AQI: Air quality index; AT: Air temperatures; RH: Relative humidity; WS: Wind speed; IQR: Inter-quartile range; BMI: Body mass index; AAQS: Ambient air quality standard; BPM: Beat per minute; OC: Organic carbon; EC: Element carbon; Cl: Confidence interval.

\section{Declarations}

\section{Ethics approval and consent to participate}

All subjects were willing to participate in this study, including questionnaire survey, physical examination, and urine sample collection. All participants signed informed consent forms before participating. The study was approved by the Biomedical Ethics Committee of the Health Science Center of Xi'an Jiaotong University, China (registration number: 2018-532).

\section{Consent for publication}

All participants signed informed consent forms and agreed their data for publication.

\section{Availability of data and materials}

All data generated or analyzed during this study are included in the article and its supplementary information file.

\section{Competing interests}

The authors declare that they have no known competing financial interests or personal relationships that could have appeared to influence the work reported in this paper.

\section{Authors' contributions}

RF conducted statistical analyses, interpreted the health-related data and drafted the manuscript. HX conceived of the study and contributed to study design, statistical analyses, drafting of the manuscript and had ultimate oversight over study design and administration. $\mathrm{KH}$ and ZW contributed to healthrelated data collection and did the experimental analysis. $\mathrm{BH}, \mathrm{RL}$, and $\mathrm{XN}$ assisted in the analyses of biomarkers. KFH and ZS contributed to the concept and design of the study. JS, BZ, and PL assisted in the recruitment of subjects, coordination, conduction on the study. All co-authors reviewed the manuscript.

\section{Funding}

This study was supported by the National Natural Science Foundation of China (41877376), the Key Research and Development Program of Shaanxi Province (2018-ZDXM3-01) and the Key Project of 
Natural Science Basic Research of Shaanxi Province (2019JZ-36).

\section{Acknowledgements}

We are grateful to all the participants in the study and appreciate their cooperation in data collection during the campaign.

\section{Additional information}

Fig. S1 and Table S1 accompany this manuscript can be found in Supplementary Information (SI).

\section{References}

1. Zhao H, Yang G, Xiu A, Zhang X. A High Resolution Emission Inventory of Domestic Burning in Rural Region of Northeast China Based on Household Consumption. Chinese Geog Sci. 2020;30(5):92133.

2. Liao J, Zimmermann Jin A, Chafe ZA, Pillarisetti A, Yu T, Shan M, Yang X, Li H, Liu G, Smith KR. The impact of household cooking and heating with solid fuels on ambient PM 2.5 in peri-urban Beijing. Atmos Environ. 2017;165:62-72.

3. Sun J, Wang J, Shen Z, Huang Y, Zhang Y, Niu X, Cao J, Zhang Q, Xu H, Zhang N, et al. Volatile organic compounds from residential solid fuel burning in Guanzhong Plain, China: Source-related profiles and risks. Chemosphere. 2019;221:184-92.

4. Pollard SL, Williams DA, Breysse PN, Baron PA, Grajeda LM, Giman RH, Miranda JJ, Checkley W, et al. A cross-sectional study of determinants of indoor environmental exposures in households with and without chronic exposure to biomass fuel smoke. Environ Health. 2014;13:21.

5. Li Y, Xu H, Wang J, Ho SSH, He K, Shen Z, Ning Z, Sun J, Li L, Lei R, et al. Personal exposure to PM2.5bound organic species from domestic solid fuel combustion in rural Guanzhong Basin, China:

Characteristics and health implication. Chemosphere. 2019;227:53-62.

6. Wang D, Li Q, Shen G, Deng J, Zhou W, Hao J, Jiang J. Significant ultrafine particle emissions from residential solid fuel combustion. Sci Total Environ. 2020;715:136992.

7. Li L, Yang A, He X, Liu J, Ma Y, Niu J, Luo B. Indoor air pollution from solid fuels and hypertension: A systematic review and meta-analysis. Environ Pollut. 2020;259:113914.

8. Hystad P, Duong M, Brauer M, Larkin A, Arku R, Kurmi OP, Fan WQ, Avezum A, Azam I, Chifamba J, et al. Health Effects of Household Solid Fuel Use: Findings from 11 Countries within the Prospective Urban and Rural Epidemiology Study. Environ Health Perspect. 2019;127(5):57003.

9. Bai L, He Z, Li C, Chen Z. Investigation of yearly indoor/outdoor $\mathrm{PM}_{2.5}$ levels in the perspectives of health impacts and air pollution control: Case study in Changchun, in the northeast of China. Suatain Cities Soc. 2020;53:101871.

10. Karottki DG, Spilak M, Frederiksen M, Gunnarsen L, Brauner EV, Kolarik B, Andersen ZJ, Sigsgaard T, Barregard L, Strandberg B, Sallsten G, Moller P, Loft S. An indoor air filtration study in homes of 
elderly: cardiovascular and respiratory effects of exposure to particulate matter. Environ Health. 2013;12:116.

11. Zhou Y, Xing X, Lang J, Chen D, Cheng S, Wei L, Wei X, Liu C. A comprehensive biomass burning emission inventory with high spatial and temporal resolution in China. Atmos Chem Phys. 2017;17(4):2839-64.

12. Chafe ZA, Brauer M, Klimont Z, Van Dingenen R, Mehta S, Rao S, Riahi K, Dentener F, Smith KR. Household cooking with solid fuels contributes to ambient PM2.5 air pollution and the burden of disease. Environ Health Perspect. 2014;122(12):1314-20.

13. He K, Xu H, Feng R, Shen Z, Li Y, Zhang Y, Sun J, Zhang Q, Zhang T, Yang L, et al: Characteristics of indoor and personal exposure to particulate organic compounds emitted from domestic solid fuel combustion in rural areas of northwest China. Atmospheric Research 2021, 248.

14. Huang W, Baumgartner J, Zhang Y, Wang Y, Schauer JJ. Source apportionment of air pollution exposures of rural Chinese women cooking with biomass fuels. Atmos Environ. 2015;104:79-87.

15. Li Q, Jiang J, Wang S, Rumchev K, Mead-Hunter R, Morawska L, Hao J. Impacts of household coal and biomass combustion on indoor and ambient air quality in China: Current status and implication. Sci Total Environ. 2017;576:347-61.

16. Yang G, Wang Y, Zeng Y, Gao GF, Liang X, Zhou M, Wan X, Yu S, Jiang Y, Naghavi M, et al. Rapid health transition in China, 1990-2010: findings from the Global Burden of Disease Study 2010. The Lancet. 2013;381(9882):1987-2015.

17. Kim KH, Jahan SA, Kabir E. A review of diseases associated with household air pollution due to the use of biomass fuels. J Hazard Mater. 2011;192(2):425-31.

18. Yin P, Brauer M, Cohen AJ, Wang H, Li J, Burnett RT, Stanaway JD, Causey K, Larson S, Godwin W, et al. The effect of air pollution on deaths, disease burden, and life expectancy across China and its provinces, 1990-2017: an analysis for the Global Burden of Disease Study 2017. The Lancet Planetary Health. 2020;4(9):e386-98.

19. Epstein MB, Bates MN, Arora NK, Balakrishnan K, Jack DW, Smith KR. Household fuels, low birth weight, and neonatal death in India: the separate impacts of biomass, kerosene, and coal. Int $\mathrm{J}$ Hyg Environ Health. 2013;216(5):523-32.

20. Torres-Dosal A, Perez-Maldonado IN, Jasso-Pineda Y, Martinez Salinas RI, Alegria-Torres JA, DiazBarriga F. Indoor air pollution in a Mexican indigenous community: evaluation of risk reduction program using biomarkers of exposure and effect. Sci Total Environ. 2008;390(2-3):362-8.

21. Dutta A, Roychoudhury S, Chowdhury S, Ray MR. Changes in sputum cytology, airway inflammation and oxidative stress due to chronic inhalation of biomass smoke during cooking in premenopausal rural Indian women. Int J Hyg Environ Health. 2013;216(3):301-8.

22. Sun J, Shen Z, Zeng Y, Niu X, Wang J, Cao J, Gong X, Xu H, Wang T, Liu H, et al. Characterization and cytotoxicity of PAHs in PM2.5 emitted from residential solid fuel burning in the Guanzhong Plain, China. Environ Pollut. 2018;241:359-68. 
23. Misra A, Longnecker MP, Dionisio KL, Bornman RMS, Travlos GS, Brar S, Whitworth KW. Household fuel use and biomarkers of inflammation and respiratory illness among rural South African Women. Environ Res. 2018;166:112-6.

24. Yang D, Yang X, Deng F, Guo X. Ambient air Pollution and Biomarkers of Health Effect. Advances in Experimental Medicine and Biology 1017, DOI 10.1007/978-981-10-5657-4\$44.

25. Dutta A, Ray MR, Banerjee A. Systemic inflammatory changes and increased oxidative stress in rural Indian women cooking with biomass fuels. Toxicol Appl Pharmacol. 2012;261(3):255-62.

26. Jiang S, Bo L, Gong C, Du X, Kan H, Xie Y, Song W, Zhao J. Traffic-related air pollution is associated with cardio-metabolic biomarkers in general residents. Int Arch Occup Environ Health. 2016;89(6):911-21.

27. Pilger A, Rudiger HW. 8-Hydroxy-2'-deoxyguanosine as a marker of oxidative DNA damage related to occupational and environmental exposures. Int Arch Occup Environ Health. 2006;80(1):1-15.

28. Gong J, Zhu T, Kipen H, Wang G, Hu M, Guo Q, Ohman-Strickland P, Lu SE, Wang Y, Zhu P, et al. Comparisons of ultrafine and fine particles in their associations with biomarkers reflecting physiological pathways. Environ Sci Technol. 2014;48(9):5264-73.

29. Commodore AA, Zhang JJ, Chang Y, Hartinger SM, Lanata CF, Mausezahl D, Gil Al, Hall DB, AguilarVillalobos M, Vena JE, et al. Concentrations of urinary 8-hydroxy-2'-deoxyguanosine and 8isoprostane in women exposed to woodsmoke in a cookstove intervention study in San Marcos, Peru. Environ Int. 2013;60:112-22.

30. Pelletier G, Rigden M, Kauri LM, Shutt R, Mahmud M, Cakmak S, Kumarathasan P, Thomson EM, Vincent R, Broad G, et al. Associations between urinary biomarkers of oxidative stress and air pollutants observed in a randomized crossover exposure to steel mill emissions. Int $\mathrm{J}$ Hyg Environ Health. 2017;220(2 Pt B):387-94.

31. Fan R, Li J, Chen L, Xu Z, He D, Zhou Y, Zhu Y, Wei F, Li J. Biomass fuels and coke plants are important sources of human exposure to polycyclic aromatic hydrocarbons, benzene and toluene. Environ Res. 2014;135:1-8.

32. Shaanxi Provincial Bureau of Statistics. 2019. Shaanxi Statistical Yearbook 2019. China Statistics Press; 2019.

33. PRC national bureau of statistics. China Energy Statistical Yearbook 2019. Beijing: China Statisticas Press; 2019.

34. Xu H, Li Y, Guinot B, Wang J, He K, Ho KF, Cao J, Shen Z, Sun J, Lei Y, et al. Personal exposure of PM2.5 emitted from solid fuels combustion for household heating and cooking in rural Guanzhong Plain, northwestern China. Atmos Environ. 2018;185:196-206.

35. Ministry of Ecology and Environment of the People's Republic of China. GB 3095 - 2012, Ambient Air Quality Standard. Beijing: China Standard Press; 2018.

36. US EPA, 2013. Technical Assistance Document for the Reporting of Daily Air Quality - the Air Quality Index (AQI). US Environmental Protection Agency EPA-454/B -13-001. 
37. Sun J, Shen Z, Cao J, Zhang L, Wu T, Zhang Q, Yin X, Lei Y, Huang Y, Huang RJ, et al. Particulate matters emitted from maize straw burning for winter heating in rural areas in Guanzhong Plain, China: Current emission and future reduction. Atmos Res. 2017;184:66-76.

38. Tian J, Ni H, Cao J, Han Y, Wang Q, Wang X, Chen LWA, Chow JC, Watson JG, Wei C, et al. Characteristics of carbonaceous particles from residential coal combustion and agricultural biomass burning in China. Atmos Pollut Res. 2017;8(3):521-7.

39. Wu X, Chen C, Vu TV, Liu D, Baldo C, Shen X, Zhang Q, Cen K, Zheng M, He K, et al. Source apportionment of fine organic carbon $(\mathrm{OC})$ using receptor modelling at a rural site of Beijing: Insight into seasonal and diurnal variation of source contributions. Environ Pollut. 2020;266(Pt 1):115078.

40. Sérgio Chiarelli P, Amador Pereira LA, Nascimento Saldiva PHd, Ferreira Filho C, Bueno Garcia ML, Ferreira Braga AL, Conceição Martins L. The association between air pollution and blood pressure in traffic controllers in Santo André, São Paulo, Brazil. Environ Res. 2011;111(5):650-5.

41. Pangaribuan $\mathrm{M}$, Chuang $\mathrm{K}-\mathrm{J}$, Chuang $\mathrm{H}-\mathrm{C}$. Association between exposures to air pollution and biomarkers of cardiovascular disease in Northern Taiwan. Atmos Pollut Res. 2019;10(4):1250-9.

42. Zhao A, Chen R, Wang C, Zhao Z, Yang C, Lu J, Chen X, Kan H. Associations between sizefractionated particulate air pollution and blood pressure in a panel of type II diabetes mellitus patients. Environ Int. 2015;80:19-25.

43. Das A, Habib G, Vivekanandan P, Kumar A. Reactive oxygen species production and inflammatory effects of ambient PM2.5 -associated metals on human lung epithelial A549 cells "one year-long study": The Delhi chapter. Chemosphere 2021, 262.

44. Longhin E, Holme JA, Gualtieri M, Camatini M, Øvrevik J. Milan winter fine particulate matter (wPM2.5) induces IL-6 and IL-8 synthesis in human bronchial BEAS-2B cells, but specifically impairs IL-8 release. Toxicol In Vitro. 2018;52:365-73.

45. Yao Y, Wang D, Ma H, Li C, Chang X, Low P, Hammond SK, Turyk ME, Wang J, Liu S. The impact on Tregulatory cell related immune responses in rural women exposed to polycyclic aromatic hydrocarbons (PAHs) in household air pollution in Gansu, China: A pilot investigation. Environ Res. 2019;173:306-17.

46. Wang T, Feng W, Kuang D, Deng Q, Zhang W, Wang S, He M, Zhang X, Wu T, Guo H. The effects of heavy metals and their interactions with polycyclic aromatic hydrocarbons on the oxidative stress among coke-oven workers. Environ Res. 2015;140:405-13.

47. Banerjee A, Mondal NK, Das D, Ray MR. Neutrophilic inflammatory response and oxidative stress in premenopausal women chronically exposed to indoor air pollution from biomass burning. Inflammation. 2012;35(2):671-83.

48. Luo Y, Zhong Y, Pang L, Zhao Y, Liang R, Zheng $X$. The effects of indoor air pollution from solid fuel use on cognitive function among middle-aged and older population in China. Sci Total Environ. 2021;754:142460.

49. Wilker EH, Preis SR, Beiser AS, Wolf PA, Au R, Kloog I, Li W, Schwartz J, Koutrakis P, DeCarli C, et al. Long-term exposure to fine particulate matter, residential proximity to major roads and measures of 
brain structure. Stroke. 2015;46(5):1161-6.

50. Tan C, Lu S, Wang Y, Zhu Y, Shi T, Lin M, Deng Z, Wang Z, Song N, Li S, et al. Long-term exposure to high air pollution induces cumulative DNA damages in traffic policemen. Sci Total Environ. 2017;593-594:330-6.

51. Liu T, Song Y, Chen R, Zheng R, Wang S, Li L. Solid fuel use for heating and risks of breast and cervical cancer mortality in China. Environ Res. 2020;186:109578.

52. Wang C, Chen R, Zhao Z, Cai J, Lu J, Ha S, Xu X, Chen X, Kan H. Particulate air pollution and circulating biomarkers among type 2 diabetic mellitus patients: the roles of particle size and time windows of exposure. Environ Res. 2015;140:112-8.

53. Bowatte G, Lodge CJ, Knibbs LD, Lowe AJ, Erbas B, Dennekamp M, Marks GB, Giles G, Morrison S, Thompson B, et al. Traffic-related air pollution exposure is associated with allergic sensitization, asthma, and poor lung function in middle age. J Allergy Clin Immunol. 2017;139(1):122-9 e121.

54. Moller P, Danielsen PH, Karottki DG, Jantzen K, Roursgaard M, Klingberg H, Jensen DM, Christophersen DV, Hemmingsen JG, Cao Y, et al. Oxidative stress and inflammation generated DNA damage by exposure to air pollution particles. Mutat Res Rev Mutat Res. 2014;762:133-66.

55. Shrine N, Portelli MA, John C, Soler Artigas M, Bennett N, Hall R, Lewis J, Henry AP, Billington CK, Ahmad A, et al. Moderate-to-severe asthma in individuals of European ancestry: a genome-wide association study. The Lancet Respiratory Medicine. 2019;7(1):20-34.

56. Wang G, Zhao J, Jiang R, Song W. Rat lung response to ozone and fine particulate matter (PM2.5) exposures. Environ Toxicol. 2015;30(3):343-56.

57. Zhao T, Markevych I, Standl M, Schikowski T, Berdel D, Koletzko S, Jorres RA, Nowak D, Heinrich J. Short-term exposure to ambient ozone and inflammatory biomarkers in cross-sectional studies of children and adolescents: Results of the GINIplus and LISA birth cohorts. Environ Pollut. 2019;255(Pt 2):113264.

58. Basu S, Kadiiska MB. Ozone exposure effect on systemic prostaglandin F2alpha in rat plasma and urine may not reveal pulmonary damage through inflammation. Prostaglandins Leukot Essent Fatty Acids. 2017;126:79-83.

59. Ji X, Han M, Yun Y, Li G, Sang N. Acute nitrogen dioxide (NO2) exposure enhances airway inflammation via modulating Th1/Th2 differentiation and activating JAK-STAT pathway. Chemosphere. 2015;120:722-8.

60. Hernandez ML, Harris B, Lay JC, Bromberg PA, Diaz-Sanchez D, Devlin RB, Kleeberger SR, Alexis NE, Peden DB. Comparative airway inflammatory response of normal volunteers to ozone and lipopolysaccharide challenge. Inhal Toxicol. 2010;22(8):648-56.

61. Bromberg PA. Mechanisms of the acute effects of inhaled ozone in humans. Biochim Biophys Acta. 2016;1860(12):2771-81.

\section{Figures}




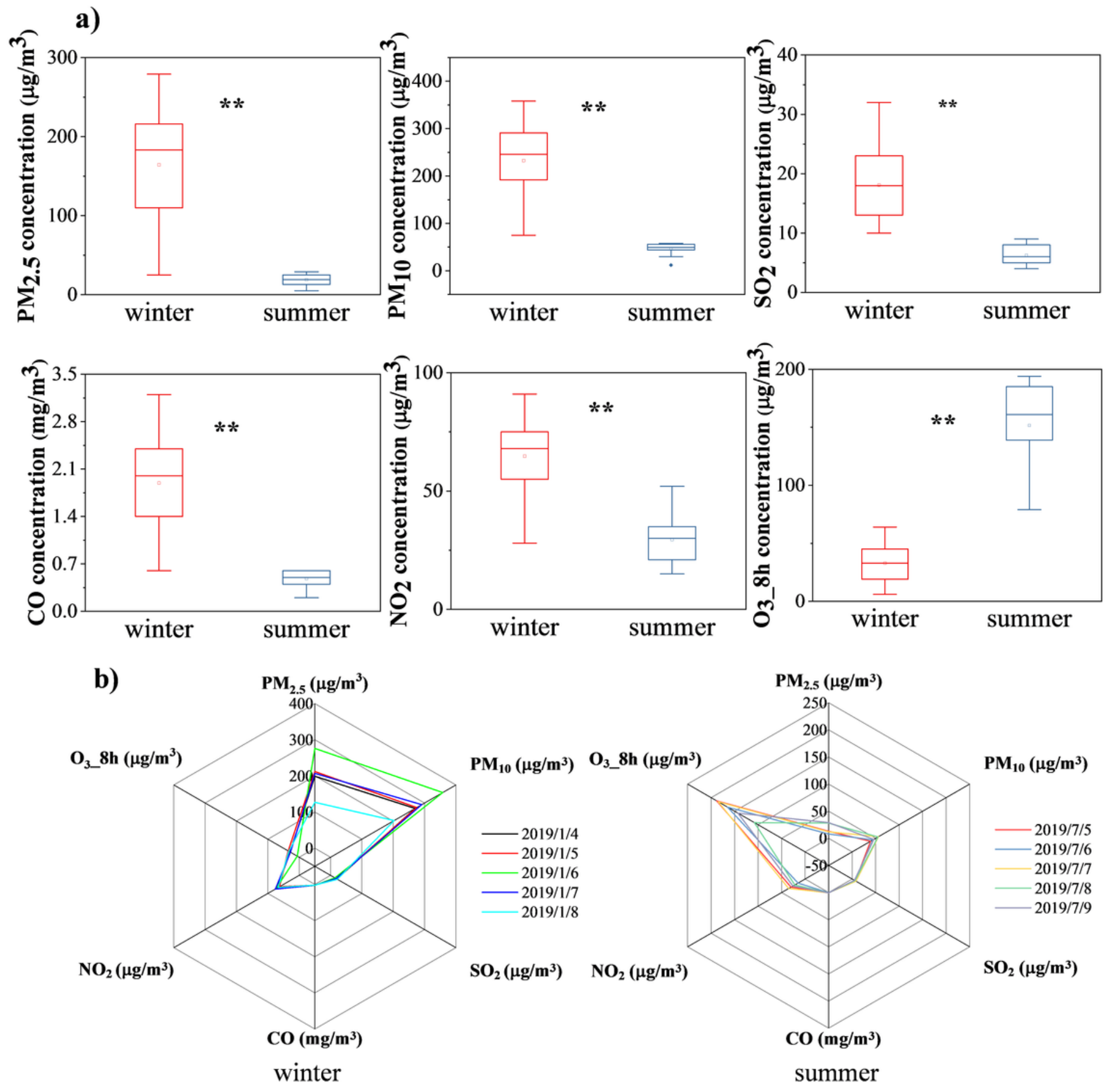

\section{Figure 1}

a) Concentrations of six air pollutants during the sampling periods in winter and summer (the box plots indicate the minimum, 1st, 25th, 50th, 75th, 99th, and maximum percentiles). b) Radar charts of major air pollutants during the sampling periods in winter and summer. 
a)

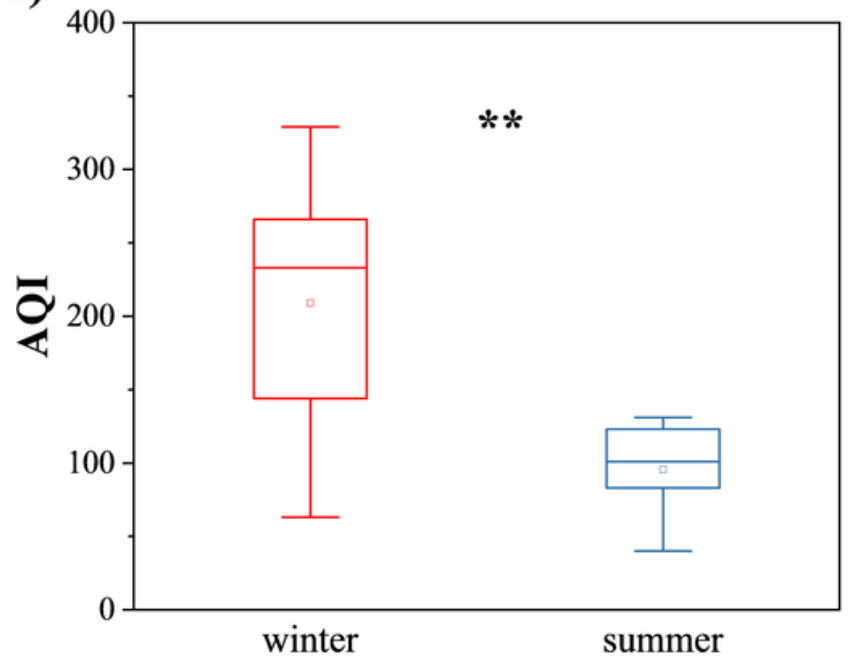

b)
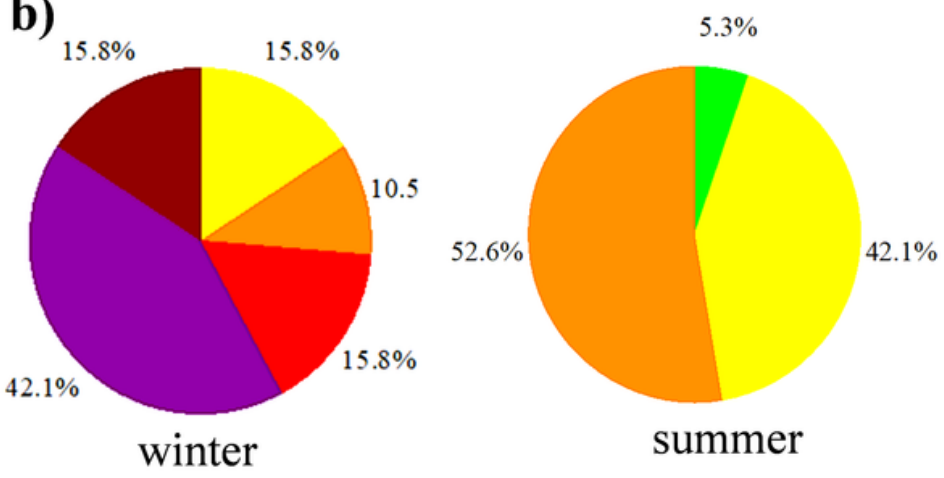

Good

Moderate

Unhealthy

Hazardous

\section{Figure 2}

a) Air quality index (AQI) during the sampling period in winter and summer (the box plots indicate the minimum, 1st, 25th, 50th, 75th, 99th, and maximum percentiles). b) Distribution of AQI values in winter and summer.
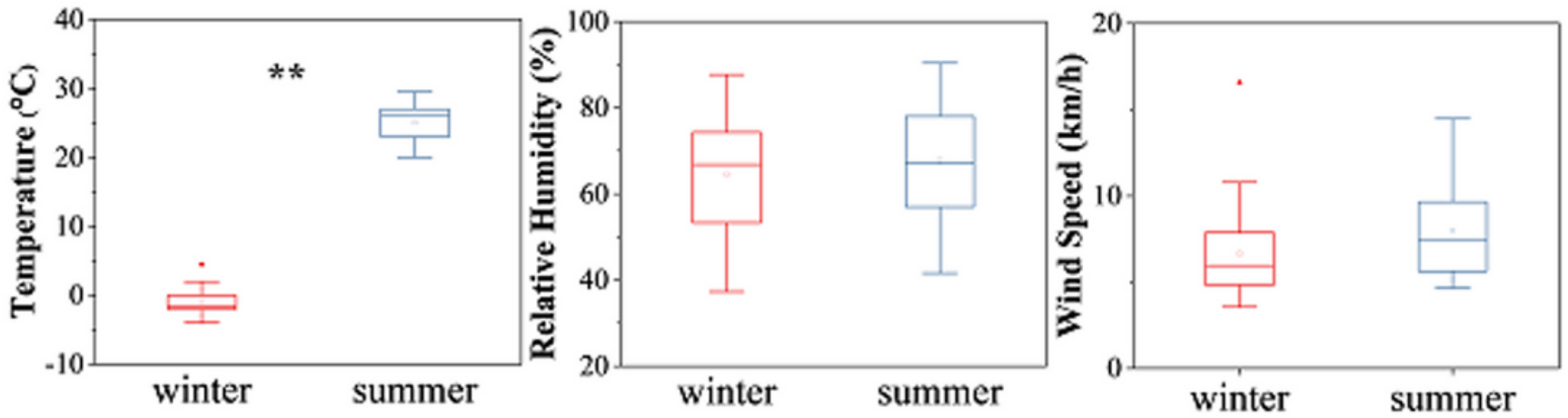

Figure 3

Meteorological parameters during the sampling periods in winter and summer (the box plots indicate the minimum, 1st, 25th, 50th, 75th, 99th, and maximum percentiles). 

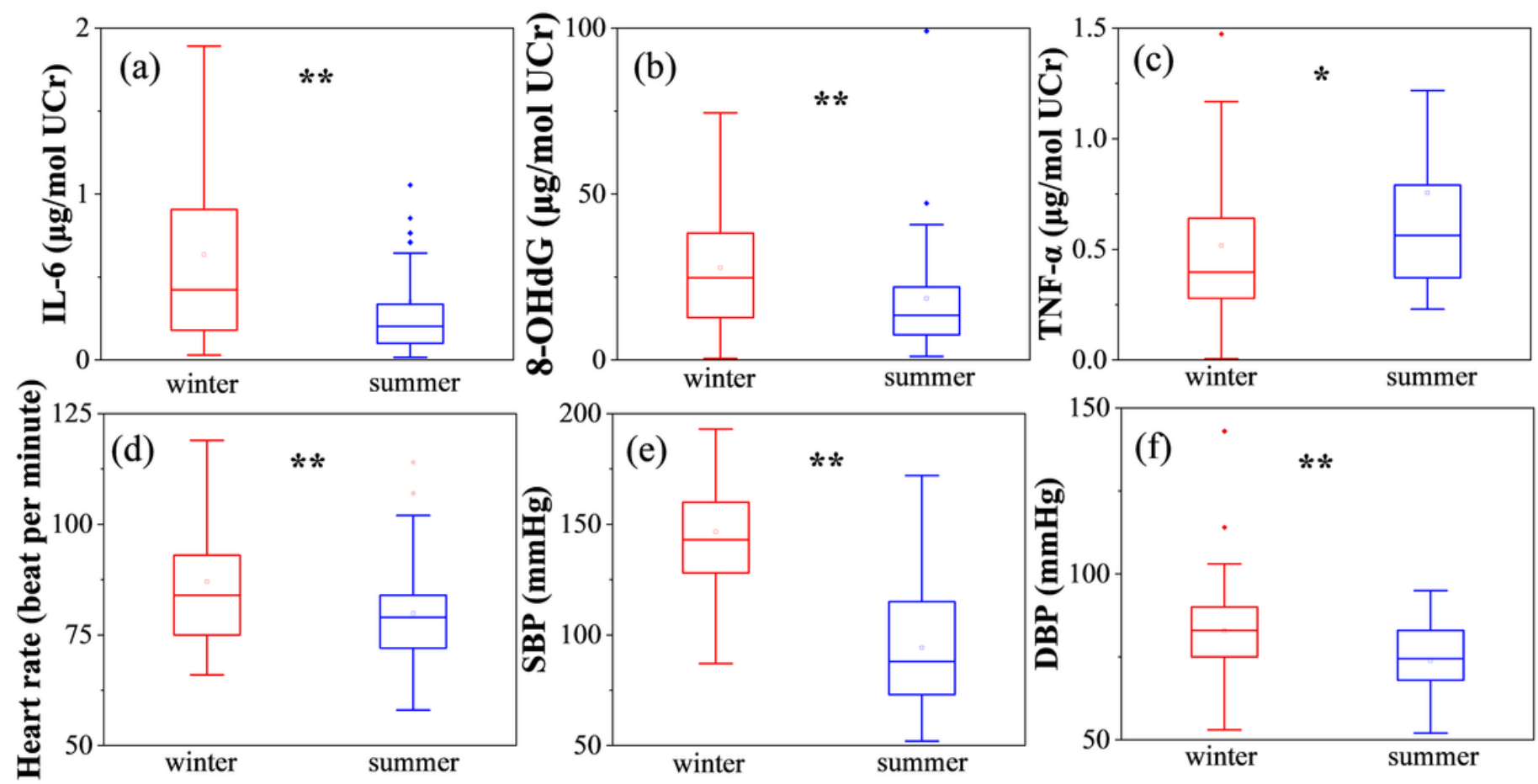

\section{Figure 4}

Biomarkers in the urine samples of participants as well as heart rate and blood pressure in winter and summer (the box plots indicate the minimum, 1st, 25th, 50th, 75th, 99th, and maximum percentiles).
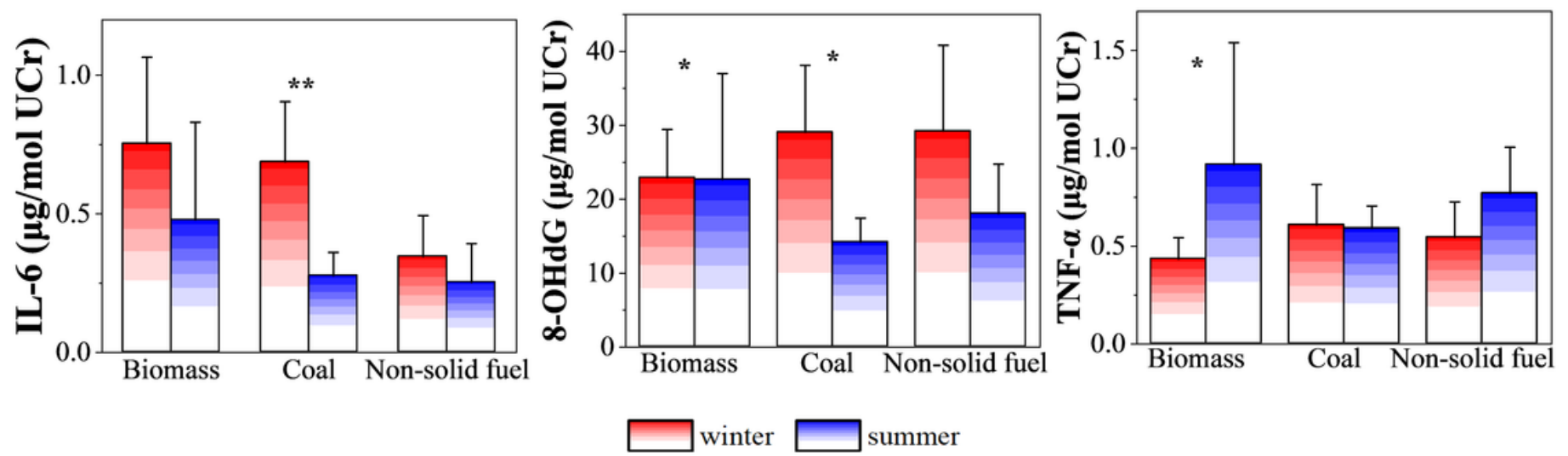

Figure 5

Biomarkers in the urine samples of participants in different fuel groups (geometric means with $95 \% \mathrm{Cls}$ are presented).

\section{Supplementary Files}

This is a list of supplementary files associated with this preprint. Click to download. 
- SolidfuelcombustiononbiomarkersinXianSI20210203.docx

Page 25/25 